\title{
Um caso raro de carcinoma de células acinares em mucosa oral
}

\section{A rare case of acinic cell carcinoma in buccal mucosa}

\author{
Luiz Arthur Barbosa da Silva' \\ LeOrik Pereira SILVA" \\ LÉLIA BATISTA SOUZA \\ Ricardo Viana Bessa Nogueira ${ }^{\text {IV }}$ \\ JosÉ de AMORIM LISBOA NetoV
}

\begin{abstract}
RESUMO
Introdução: O carcinoma de células acinares é uma neoplasia epitelial maligna rara de glândulas salivares que afeta predominantemente a glândula parótida na população feminina. Ocorrências menos comuns dessa neoplasia são relatadas no palato, seio maxilar, lábios e mucosa jugal. A recorrência desses tumores após cirurgia é de aproximadamente $35 \%$, e está relacionada a tumores diagnosticados tardiamente e com presença de metástase no momento do diagnóstico.

Objetivo: Relatar um caso raro de um tumor em glândula salivar menor e comparar os achados clínicos com outros casos relatados na literatura.

Relato de Caso: Paciente do sexo feminino, 35 anos de idade, apresentou um nódulo doloroso de aproximadamente $2 \mathrm{~cm}$ em mucosa jugal que foi diagnosticado inicialmente como um schwanoma devido aos seus achados clínicos e radiológicos. Após biópsia incisional, o exame histopatológico e imunoistoquímico revelou um carcinoma de células acinares. Uma tomografia por emissão de pósitrons não revelou presença de metástases. Conclusão: Nódulos submucosos orais podem representar neoplasias malignas e mesmo diante de uma hipótese diagnóstica de tumor benigno, recomenda-se uma biopsia incisional imediata para obtenção de um diagnóstico precoce e conduta terapêutica adequada nesses casos.
\end{abstract}

Palavras-chave: Glândulas Salivares. Neoplasias Bucais. Carcinoma de Células Acinares. Diagnóstico. Relatos de Casos.

\begin{abstract}
Introduction: Acinic cell carcinoma is a rare epithelial malignant neoplasm of salivary glands affecting predominantly the parotid gland in female population. Unusual occurrences of this neoplasm are reported in palate, maxillary sinus, lip, and buccal mucosa. The recurrence of these tumors after surgical treatment is approximately $35 \%$ being associated with tumors tardily diagnosed and presence of metastasis at the moment of diagnosis.

Objective: To report a rare case of a minor salivary gland tumor and compare the clinical findings with other cases reported in the literature.

Case Report: A female patient, 35 years, showed a painful nodule with approximately $2 \mathrm{~cm}$ in the buccal mucosa which was diagnosed initially as a schwannoma due to their clinical and radiological findings. After incisional biopsy, histopathologic and immunohistochemical evaluation revealed an Acinic cell carcinoma. A Positron Emission Tomography showed the absence of metastasis.

Conclusion: Oral submucosal nodules may represent malignancies and even before a diagnosis of benign tumor, it is recommended an immediate incisional biopsy to obtain an early diagnosis and appropriate therapeutic approach in these cases.
\end{abstract}

Key-words: Salivary Glands. Mouth Neoplasms. Acinic cell carcinoma. Diagnosis. Case reports.

\footnotetext{
Universidade Federal do Rio Grande do Norte (UFRN) Caicó/RN - Brasil Universidade Federal do Rio Grande do Norte (UFRN) Caicó/RN - Brasil

"I Universidade Federal do Rio Grande do Norte (UFRN) Caicó/RN - Brasil

Universidade Federal de Alagoas (UFAL), Rio Largo/AL - Brasil

Universidade Federal de Alagoas (UFAL), Rio Largo/AL - Brasil
} 


\section{INTRODUÇÃO}

Descrito pela primeira vez em 1892 por Nasse, o carcinoma de células acinares (CCA) foi originalmente denominado de "tumor de células acinares", pois havia incerteza acerca do seu comportamento clínico. Sessenta anos mais tarde, Foote Jr. e Frazell ${ }^{1}$ reconheceram o comportamento maligno desse tumor. $O$ CCA é uma neoplasia maligna incomum, representando cerca de $3-7 \%$ de todos os tumores das glândulas salivares com 90\% dos casos acometendo a glândula parótida, sendo ainda mais raro em glândulas salivares menores. ${ }^{2,3}$

O CCA possui diferenciação acinar serosa, caracterizado por apresentar grânulos citoplasmáticos de secreção zimogênio e alguns casos também apresentam células claras, oncocíticas e vacuoladas. Esse tumor pode ter uma variedade de tipos histomorfológicos, entre eles, um padrão sólido, microcístico, folicular e papilar-cístico, normalmente manifesta comportamento biológico de baixo grau de malignidade e não exibe comumente atipias, mitoses ou áreas de necrose..$^{2,3,4}$

Tentativas de estabelecer uma gradação histopatológica de malignidade não obtiveram sucesso, no entanto, tumores com mitoses atípicas, necrose, invasão neural e acentuado pleomorfismo apresentam um pior prognóstico. ${ }^{3,4}$ Atualmente, tem sido descrita a transformação para tumor de alto grau que apresenta um comportamento biológico diferente, pior evolução clínica e prognóstico pobre. ${ }^{2}$ Outros fatores que também estão associados ao prognóstico dos pacientes: tamanho do tumor primário, parestesia, invasão local, rápido crescimento tumoral e a presença de metástases regionais ou distantes. . $^{2,3,4}$
O presente trabalho teve como objetivo relatar um caso de CCA originado em glândula salivar menor, onde houve diagnóstico precoce e conduta terapêutica adequada, além de comparar o presente caso com outros relatos de CCA descritos na literatura nos últimos seis anos (2010-2016). . $^{411}$

\section{Relato do CAso}

Paciente do sexo feminino, 35 anos de idade, foi encaminhada a uma clínica de Diagnóstico Oral queixando-se de dor espontânea em região esquerda da face. Ao exame clínico nenhum tipo de alteração dentária ou na mucosa oral estava relacionado com a queixa. Foram solicitadas radiografias convencionais para investigar possíveis lesões nos ossos da face, no entanto alterações ósseas foram descartadas após avaliação.

Durante inspeção da mucosa oral e palpação na região de fundo de vestíbulo e mucosa jugal, constatou-se a presença de um nódulo submucoso com aproximadamente $2 \mathrm{~cm}$, de consistência amolecida e sintomático à pressão digital. $O$ exame clínico cervical não revelou linfadenomegalia. Não havia sinais de infecção ou exsudato inflamatório e a região acometida era normocrômica. A paciente negou doenças sistêmicas, febre recente e uso de medicações.

Ancorados nos achados clínicos, a principal hipótese diagnóstica foi de Schwanoma, um tumor neural periférico benigno que pode se apresentar como nódulo doloroso ao diagnóstico. Realizou-se biópsia incisional, tendo em vista que a lesão era maior que $1 \mathrm{~cm}$. O exame histopatológico revelou a presença de neoplasia maligna de origem glandular salivar sugestiva de CCA (Figura 1A-D). Foi realizado um painel imunohistoquímico que confirmou o diagnóstico de CCA (Tabela 1). 


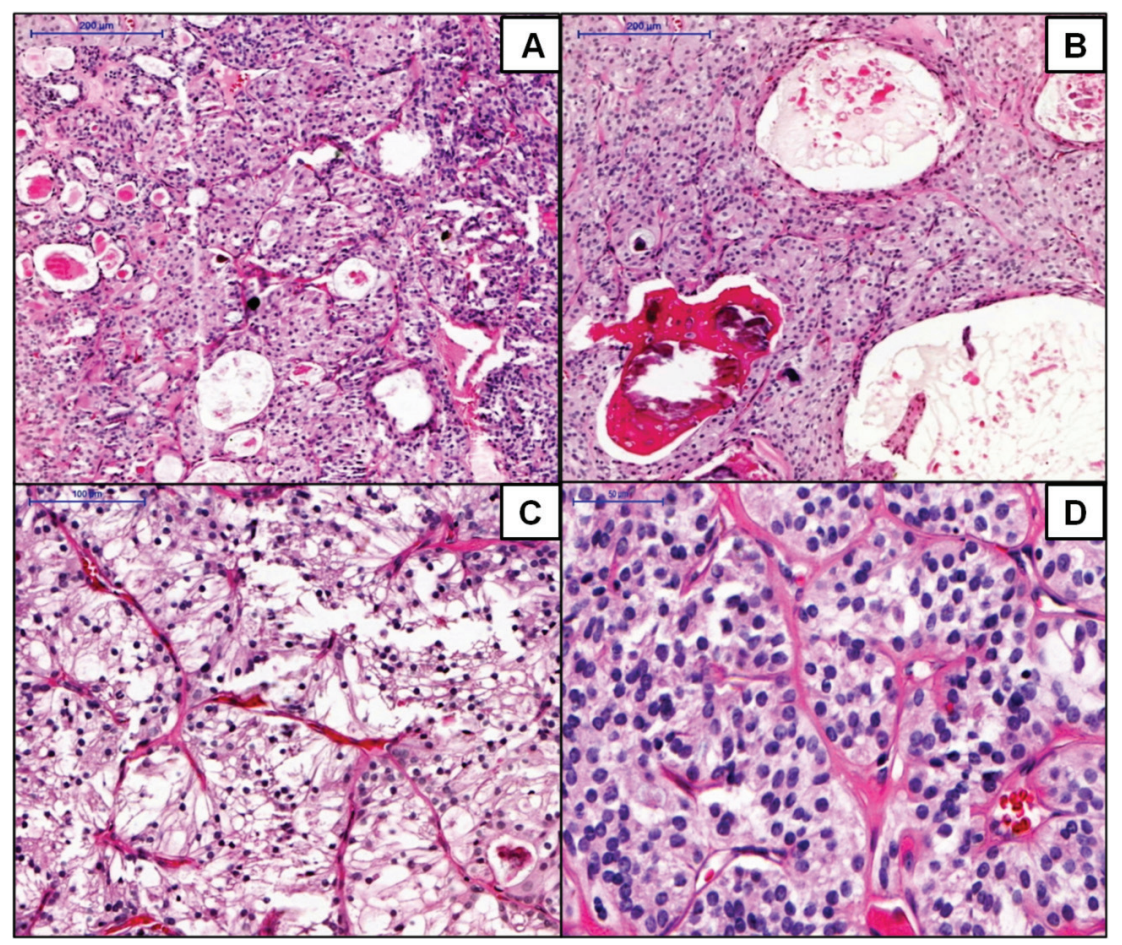

Figura 1. Fotomicrografia em HE do CCA (Panaromic Scaner Viewer). A - Espaços císticos e pseudoductais de tamanhos variados no padrão microcístico $(B a r r a=200 \mu \mathrm{m})$. B - Estruturas císticas e corpos psamoma permeando área sólida de células acinares $(B a r r a=200 \mu \mathrm{m})$. C - Observa-se padrão de células claras que são semelhantes a células acinares, porém mostra ausência de coloração citoplasmática (Barra= $100 \mu \mathrm{m})$. D - Em maior ampliação, observa-se padrão sólido de células acinares com citoplasma pouco basófilo e granuloso (Barra= 50 $\mu \mathrm{m}$ ).

Tabela 1. Painel imuno-histoquímico utilizado para confirmação do diagnóstico final.

\begin{tabular}{l|l|l|l}
\hline Anticorpo & Especificidade (Clone) & Positividade & Localização \\
\hline CK alto peso & Monoclonal (34bE12) & Positivo (focal) & Citoplasmática \\
\hline CK-8 & Monoclonal (35BH11) & Positivo & Citoplasmática \\
\hline P63 & Monoclonal (EPR5701) & Positivo (focal) & Citoplasmática \\
\hline S100 & Monoclonal (EP1576Y) & Negativo & - \\
\hline Actina de músculo liso & Monoclonal (Ab5694) & Negativo & - \\
\hline
\end{tabular}

A paciente foi encaminhada a um centro de referência em Oncologia para iniciar tratamento. Tomografia Computadorizada (TC) com contraste e Tomografia por emissão de pósitrons (PET-CT) foram realizadas para estabelecer o estadiamento do tumor e auxiliar no planejamento terapêutico. Foi observada uma lesão hiperdensa ovalada e bem delimitada com densidade de partes moles,

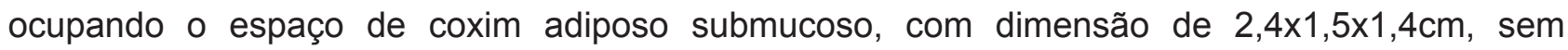
invasão do seio maxilar (Figura 2A). O PET-CT evidenciou a hipercaptação do 18-FDG (18-Flúordesoxidoglicose) na lesão (Figura 2B). 


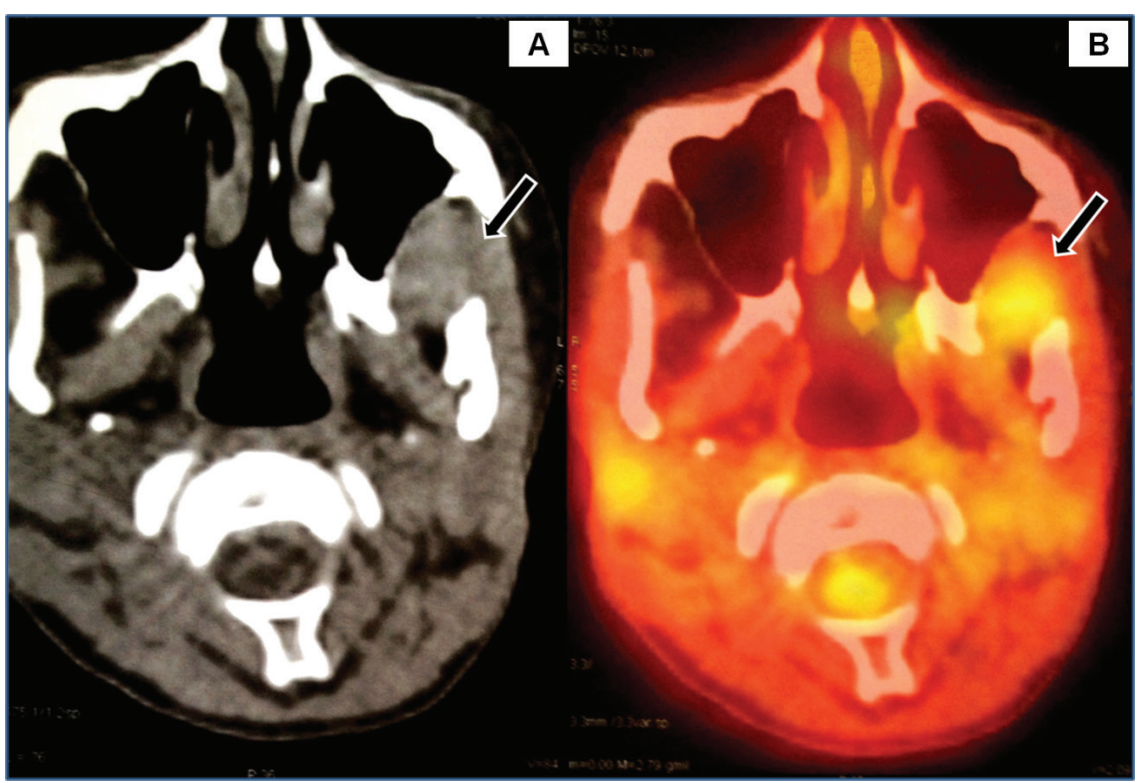

Figura 2. PET-CT e TC com contraste. A - Observa-se imagem de CT (Helicoidal) revelando presença de lesão ovalada com captação atenuada em íntimo contato com a parede do seio maxilar esquerdo (Ver Seta). B - Imagem de PET-CT evidenciando a hipercaptação do 18F-FDG (Fluordesoxiglicose) (Ver Seta).

O exame de corpo todo através do PET-CT não indicou hipercaptação em qualquer tecido regional ou distante compatível com focos de metástase (Figura 3). Dessa forma, o estadiamento TNM foi T2NOMO - Estágio II. A paciente foi submetida à ressecção cirúrgica com margens de segurança e o exame histopatológico da peça não evidenciou margens comprometidas. Há cinco anos em acompanhamento clínico, não se evidencia recidivas do tumor ou metástases.
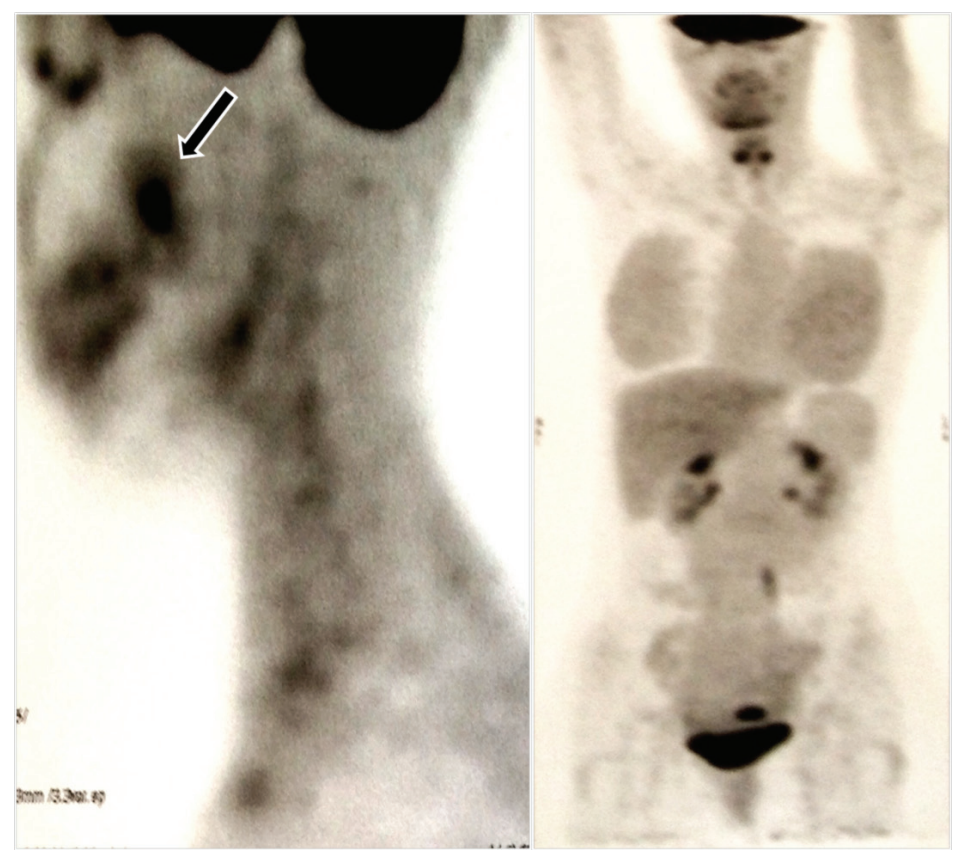

Figura 3. Formação com atenuação e hipercaptação de imagem difusa do material radioativo na região da lesão (Ver Seta - esquerda). Distribuição fisiológica do radiotraçador no encéfalo, tireoides, adrenais e endométrio, evidenciando ausência de processo metastático ativo (Direita). 


\section{Dıscussão}

A Organização Mundial da Saúde (OMS) define o CCA como "uma neoplasia epitelial maligna de glândulas salivares, em que pelo menos algum componente celular neoplásico demonstra a diferenciação acinar serosa". Acomete indivíduos em ampla faixa etária, com uma predileção por mulheres.
Normalmente são assintomáticos, o que pode resultar em diagnóstico tardio. ${ }^{3}$

A revisão dos casos de CCA em glândulas salivares menores nos últimos cinco anos (Tabela 2) mostrou uma maior incidência desses tumores como nódulos sintomáticos principalmente diagnosticados em homens com idade variável de 30 a 78 anos, sendo a mucosa jugal o sítio mais acometido. $3,4,5,6,7,8,9,10,11$

\begin{tabular}{|c|c|c|c|c|c|}
\hline Autores & $\mathbf{N}$ & Sexo & $\begin{array}{l}\text { Idade } \\
\text { (Anos) }\end{array}$ & Localização anatômica & Sintomatologia \\
\hline $\begin{array}{c}{\text { Omlie, } \text { Coutlas }^{(4)}}^{(2010)} \\
\end{array}$ & 21 & $\begin{array}{l}\text { Masc. (15) } \\
\text { Fem. (6) }\end{array}$ & Média $=48$ & $\begin{array}{l}\text { Mucosa jugal }(n=7) ; \text { palato }(n=6) \text {; lábio } \\
(n=6) \text { e Trígono retromolar }(n=2) \text {. }\end{array}$ & Ass. \\
\hline $\begin{array}{l}\text { Triantafillidou et } \\
\text { al., }{ }^{(5)}(2010)\end{array}$ & 11 & $\begin{array}{l}\text { Masc. (7) } \\
\text { Fem. (4) }\end{array}$ & Média $=70$ & $\begin{array}{l}\text { Mucosa jugal (4), maxila (2), palato } \\
\text { (2), lábio (2) e Mandíbula (1). }\end{array}$ & $\begin{array}{l}\text { Ass. (4) } \\
\text { Sin. (7) }\end{array}$ \\
\hline $\begin{array}{l}\text { Sherwani et al.. }{ }^{(6)} \\
\text { (2010). }\end{array}$ & 1 & Masc. & 50 & Palato & Ass. \\
\hline $\begin{array}{l}\text { Villeneuve et al., }{ }^{(7)} \\
\text { (2011) }\end{array}$ & 1 & Masc. & 35 & Trígono retromolar & Ass. \\
\hline Wada et al., ${ }^{(8)}(2012)$ & 1 & Masc. & 32 & Base de língua & Sin. \\
\hline Bavle et al., ${ }^{(9)}(2014)$ & 1 & Fem. & 60 & Lábio superior & Ass. \\
\hline $\begin{array}{c}\text { Ilayaraja et al., }{ }^{(10)} \\
(2014)\end{array}$ & 1 & Masc. & 69 & $\begin{array}{l}\text { Mucosa jugal, gengiva e trígono } \\
\text { retromolar }\end{array}$ & Sin. \\
\hline $\begin{array}{l}\text { Aravind et al., }{ }^{(11)} \\
\text { (2015) }\end{array}$ & 1 & Fem. & 30 & Região submandibular esquerda & Ass. \\
\hline $\begin{array}{l}\text { Presente caso. } \\
\qquad(2016)\end{array}$ & 1 & Fem. & 35 & Mucosa jugal & Sin. \\
\hline
\end{tabular}

Tabela 2. Casos de Carcinoma de Células Acinares relatados nos últimos cinco anos no PubMed (2010-2016). Ass.: Assintomático. Sin.: Sintomático. N.: número de casos. Masc.: Masculino. Fem.: Feminino.

Os padrões histológicos parecem não exercer influências no comportamento biológico e prognóstico tumoral. ${ }^{3}$ No presente caso, havia predomínio do padrão sólido, além da presença de células claras, o que poderia fazer diagnóstico diferencial com carcinoma mioepitelial ou adenocarcinoma de células claras, no entanto, a expressão imunohistoquímica descrita na Tabela 1 confirma uma diferenciação acinar/ductal (Ck-alto peso molecular e Ck-8) sem a presença de células mioepiteliais (p63 e Actina de músculo liso), que somada com características histopatológicas, confirmou o diagnóstico de CCA.

O carcinoma mioepitelial seria positivo para marcadores de células mioepiteliais como o p63 e Actina de músculo liso. O adenocarcinoma de células claras não mostra os padrões morfológicos com células acinares, estruturas císticas e corpos psamomas, esse tumor é essencialmente monótono com células claras e a expressão de marcadores imunohistoquímicos é variável, no entanto o p63 é positivo na maioria dos casos. ${ }^{12} \mathrm{O}$ carcinoma 
de células renais metastático é sempre incluído no diagnóstico diferencial dos carcinomas salivares que apresentam células claras, contudo, o carcinoma de células renais é mais vascularizado e geralmente apresenta-se predominantemente em ninhos ou crescimentos sólidos de células exclusivamente claras e raras vezes oncocíticas, esses tumores são positivos para CD10 e proteína renal. ${ }^{12}$ Nós enfatizamos que o presente caso apresentado não evidenciou padrão predominante de células claras, e o exame de PET-CT excluiu qualquer possibilidade de outros tumores malignos ou metástases.

O tratamento de escolha do CCA é a ressecção cirúrgica com margem de segurança. Estudos demonstram recorrência em $35 \%$ dos casos e metástases em $16 \%$. Múltiplas recorrências e metástases em linfonodos indicam pior prognóstico. ${ }^{3} \mathrm{~A}$ presença de metástase deve ser excluída por meio de exames complementares, como PET e TC..$^{13}$ No presente caso, esses exames confirmaram a ausência de disseminação metastática regional ou distante e a paciente encontra-se livre de doença desde o tratamento do tumor primário há cinco anos. Ressalta-se a importância do diagnóstico correto e precoce, assim como a exclusão de disseminação, para que o paciente alcance longevidade com qualidade de vida.

A detecção precoce de metástases a distância é uma das vantagens do PET/CT. Estudos recentes demonstraram que essa modalidade imagenológica tem um efeito significativo sobre a conduta terapêutica de pacientes com câncer, uma vez que auxiliam a busca precoce de sítios metastáticos do tumor com superior precisão em relação a outras técnicas. ${ }^{13}$

\section{ConsideraçõEs finAIS}

De acordo com a literatura, o CCA foi mais comum em homens com idade variável, tendo a mucosa jugal como principal localização anatômica. Destaca-se que nódulos submucosos orais podem representar neoplasias malignas como o CCA, e mesmo diante de uma hipótese clínica de tumor benigno, quando maior que $1 \mathrm{~cm}$, recomendase uma biopsia incisional imediata para obtenção do diagnóstico precoce e correto. Salienta-se ainda a importância da análise imuno-histoquímica e a realização de exames complementares para determinar o diagnóstico correto e a conduta terapêutica adequada nesses casos.

\section{REFERÊNCIAS}

1. Foote FW Jr, Frazell EL. Tumors of the major salivary glands. Cancer. 1953; 6(6):1065-133.

2. Thompson LD, Aslam MN, Stall JN, Udager AM, Chiosea S., McHugh JB. Clinicopathologic and Immunophenotypic Characterization of 25 Cases of Acinic Cell Carcinoma with High-Grade Transformation. Head Neck Pathol. 2016; 10(2):152-60.

3. Barnes L., Eveson JW, Reichart P., Sidransky D. Pathology and genetics of head and neck tumours. Lyon: IARC Press; 2005.

4. Omlie JE, Koutlas IG. Acinic cell carcinoma of minor salivary glands: a clinicopathologic study of 21 cases. J Oral Maxillofac Surg. 2010; 68(9):2053-7.

5. Triantafillidou K., Iordanidis F., Psomaderis K., Kalimeras E. Acinic cell carcinoma of minor salivary glands: a clinical and immunohistochemical study. J Oral Maxillofac Surg. 2010; 68(10):2489-96.

6. Sherwani R., Akhtar K., Ahmad M., Hasan A. Cytologic diagnosis of acinic cell carcinoma of minor salivary gland: a distinct rarely described entity. Clin Pract. 2011; 1(3):e58.

7. Villeneuve H., Tremblay S., Galiatsatos P., Hamel N., Guertin L., Morency R., Tischkowitz $M$. Acinic cell carcinoma of the retromolar trigone region: expanding the tumor phenotype in Cowden syndrome? Fam Cancer. 2011; 10(4):691-4. 
8. Wada K., Watanabe S., Ando Y., Seino Y., Moriyama $\mathrm{H}$. Acinic cell carcinoma of minor salivary gland of the base of tongue that required reconstructive surgery. Case Rep Otolaryngol. 2012; 2012:421065.

9. Bavle RM, Makarla S., Nadaf A., Narasimhamurthy $S$. Solid blue dot tumour: minor salivary gland acinic cell carcinoma. BMJ Case Rep. 2014; 2014: bcr2013200885.

10. Ilayaraja V., Prasad H., Anuthama K., Sruthi R. Acinic cell carcinoma of minor salivary gland showing features of high-grade transformation. J Oral Maxillofac Pathol. 2014; 18(1):97-101.

11. Aravind RM, Narayanan NS, Ravishankar KS, Babu NG. Acinic cell carcinoma of buccal mucosa: An unusual presentation. J Cancer Res Ther. 2015; 11(4):931-3.

12. Hellquist $H$., Skalova A. Histopathology of the Salivary Glands. Berlin: Springer; 2014.

13. Kim im JY, Lee SW, Kim JS, Kim SY, Nam SY, Choi $\mathrm{SH}$, et al. Diagnostic value of neck node status using 18F-FDG PET for salivary duct carcinoma of the major salivary glands. J Nucl Med. 2012; 53(6):881-6.

\section{Dados dos Autores}

\section{LUIZ ARTHUR BARBOSA DA SILVA}

Mestre em Patologia Oral. Doutorando do Programa de Pós-graduação em Patologia Oral da Uni- versidade Federal do Rio Grande do Norte. Natal/ RN - Brasil. larthurbarbosa@hotmail.com

\section{LEORIK PEREIRA SILVA}

Mestre em Patologia Oral. Doutorando do Programa de Pós-graduação em Patologia Oral da Universidade Federal do Rio Grande do Norte. Natal/ RN - Brasil. leorikp@gmail.com

\section{LÉLIA BATISTA SOUZA}

Doutora em Patologia Bucal. Professora Titular do Programa de Pós-graduação em Patologia Oral da Universidade Federal do Rio Grande do Norte. Natal/RN - Brasil. leliabsouza@gmail.com

\section{RICARDO VIANA BESSA NOGUEIRA}

Doutor em Odontologia. Professor Adjunto no Departamento de Cirurgia e Traumatologia Buco-maxilo-facial da Universidade Federal de Alagoas. Maceió/AL - Brasil. ricardobessa@msn.com

\section{JOSÉ DE AMORIM LISBOA NETO}

Mestre em Patologia Oral. Professor Assistente no Departamento de Patologia Geral e Oral da Universidade Federal de Alagoas. Maceió/AL - Brasil. jlisboaneto@oi.com.br

Submetido em: 11-10-2016

Aceito em: 15-2-2017 